\title{
Research on Legislative Countermeasures to the Difficulty of Executing the Fine Penalty
}

\author{
Xiao-yu Li \\ College of Information \& Business, Zhongyuan University of Technology, Henan Province, China \\ 631427825@qq.com
}

\begin{abstract}
Despite that the difficulty of executing the fine penalty becomes universal, this issue still has not gained its due attention either in the criminal substantive laws or in the procedural law-studying field. This article tries to develop systematic research covering from the executing way of fine penalty, reasons of executing difficulty to the improvements of related mating systems and others and to propose the applicable range of adjusted fine penalty, add the criminal fine exchanging institution, clarify the enforcement organization and implement in the pilot the property investigation and preservation prior to judgment institution, etc., which hopefully could make a contribution to the research of the execution of punishment.
\end{abstract}

Index Terms - Executing difficulty; property investigation; property preservation; criminal fine exchanging.

\section{Analysis of the Executing Difficulty}

The executing difficulty is of universality, even in the western countries that are of impeccable fine execution systems. According to the statistics, in China, the ratio of terminating the execution is less than $1 \%$ while that of suspending the execution reaches $90 \%$ [1]. On this difficulty of executing the fine penalty, one scholar once summarized it in four sentences that is it is hard to find the executor; it is hard to seek the property of the executed; it is hard to get the support to the executor; it is hard to deal with the subject matter of execution. [2] It involves many different reasons for the difficulty. Below are some prominent ones.

\section{A. Not All the Designing of the Fine Penalty Sentencing is Scientific.}

There are many clauses in the Specific Provisions of the current Criminal Law that could apply to the fine penalty and their specific applications could be summarized as separate sentence, selective sentence, added sentence and the sentence that must to be attached. Among them, the separate sentence could only be applied to the unit crime. The added sentence could only be applied to the Clause 325 in the Criminal Law. And the total number of clauses that the selective sentence could be applied to is only 9 . The rest are all for the sentence that must to be attached. In other words, in China, the fine penalty still exists as a measure attached to the punishment against freedom. Meanwhile the fined criminal also should bear the punishment against freedom in a short or long term.

From the perspective of the modest and restrained principle of the Criminal Law, the intention of designing and applying the fine penalty is to avoid the malpractice of the short-term punishment against freedom and it also meets the need of gradual penalty lightening; however, under the circumstance of the sentence that must to be added, the application of the fine penalty does not weaken the severity of the punishment against freedom. Moreover, the total penalty exceeds the limit of criminal liability, which causes the collision and resistance from the criminal and his family. But according to the specific regulations in the Specific Provisions of the Criminal Law, especially that of the sentence that must to be added, with knowing clearly the fine penalty probably won't be executed, the Judge has to sentence so in the court. In other words, even the criminal is sentenced to pay the fine penalty, usually the fine cannot be collected, increasing the difficulty of execution.

\section{B. The Range of Sentencing the Fine Penalty is not Clearly Stated.}

Although making some partial adjustments in the Amendment to Criminal Law (VIII), most of the fine penalty sentences in the Chinese Criminal Law adopt the unlimited mechanism, among which the percentage of multi proportions and limited mechanisms occupying is little while the day fine mechanism misses. With giving a bigger discretion to the court, the regulation of the unlimited mechanism leads to the outcome of different fines to the same criminal, especially noticing the scene that unbelievable sentenced fine penalties teem with great difference or wide gap from each other. In a review, the fine penalty mainly applies to the crimes that gain unlawful procurement of benefit. In terms of the criminal judicial practices, most of the criminals are poor, who are driven by the poverty. All the proceeds of crime are either squandered by the criminals or confiscated in accordance with the laws. So the criminals are still not capable of paying the fine penalty.

In 2000, the Regulations on Issues Applied to Propertyrelated Penalties issued by the Supreme People's Court clearly states that the court should have an full consideration of the criminal's capability of paying fine with a reference of his circumstances of crime such as his illegal earnings and losses he causes, etc., and give a sentence of fine penalty according to laws. Whereas in the reality, many courts hold divergences on if the court should consider the criminal's financial capability. It may be based on the consideration of the principle that all are equal before the law or from the recognition that the criminal has difficulty in paying the fine penalty. On the other hand, it also makes the fine execution harder. 


\section{There LACKS of the Incentive and the Supervision Systems for the Fine Penalty Execution.}

Though the court is responsible for carrying out the fine penalty, the beneficiary of the penalty belongs to this country. After collecting the fine, the court turns it over directly to the local finance. The execution subject does not gain any benefit directly from it but has a hard time in execution, which occupies a lot of time and energy of the court personnel. It also becomes a burden to them therefore the personnel does not play an active role in it or attach importance to the execution. Besides, the execution of fine penalty is different from that in the civil executions which are applied in accordance with law. There lacks the necessary and efficient supervision to the execution's effect and process. In the Quantitative Evaluation Index System for courts at all levels, the ratio of terminating a fine penalty is rarely mentioned.

\section{The Personal Property Management and Credit Systems are Missing.}

Now, the ways citizens earn diversify and the financial products gradually become flexible. But the powerful Finance Supervision System and Institution has not been built up yet and the Citizens' Personal Property Management System is missing. It's pretty easy for the criminal to transfer or conceal his property. Without abovementioned behaviors, there also exist many scenes of unclear property rights caused in the process of property transferring or by historical problems or law flaws. It makes harder of executing the fine penalty. The difficulty of executing the fine penalty could be regarded as one of the signs showing the great missing of the social integrity. And the significant earth nurturing its existence is the wrong conceptions of repudiating debts and maliciously evading the legal obligations. The citizens' Personal Credit System and its Evaluation System have not been improved. To some extent, it boosts some criminals holding a fluke mind to impede the execution of fine penalty.

\section{Solutions in Legislative Countermeasures}

Viewing from the present legislative construction on the fine penalty, there are missing the specific institutional regulations that could clarify the issues such as the fine penalty's executive organization, measures, objections to execution, the suspension and the termination of the execution and the fine penalty exchanging, etc., which shows a severe absence of legislation. In allusion to these shortcomings, I will explain the practical countermeasures from different aspects.

\section{A. Adjust the Application of Fine Penalty and Add the Fine Penalty Exchanging System}

Firstly, enlarge the applicable range of the separate and selective sentences and change part of the sentence that must to be attached to the add sentence. Reviewing the legislative regulations each country makes on the applications of fine penalty, it could be divided into three main categories that is firstly, applying only fine to minor crimes while attaching the fine penalty to the felonies; secondly, the main subjects to whom apply the fine penalty are the criminals who seek unlawful procurement of benefit; and lastly, the fine penalty could be applied to most of the crimes. Chinese legislative case belongs to the second category that the fine is mainly charged from the crimes with the unlawful procurement of benefit such as the larceny and the crime of manufacturing or selling counterfeit or inferior products. But generally speaking, there are few crimes that could be sentenced for the separate or the selective sentences. It suggests making some proper breakthroughs in the seven provisions on separate or selective sentences, which states that the sentences could be applied to the criminals who are situational or first offender, who confess their crimes or have the behavior of meritorious service, who is less than 18 years old in the time of their crime, who are preparing for a crime, whose crime is suspended or terminated, who commit a crime under coercive, who disgorge ill-gotten gains with showing the repentance and others. Besides, it is a pity that now there is no regulation in the Criminal Law on applying the fine penalty to the typical duty crimes that seek the unlawful procurement of benefit such as the crime of corruption, the bribery crime and the crime of misappropriating public fund. It does harm to the punishment to the anticrime. It suggests that we should break the restriction, designing it as the added sentence or the sentence that must to be attached[3] The criminal negligence or the minor crime that is sentenced by the main Criminal Law as a fixed-term imprisonment less than 3 years could be applied the separate or selective sentence. It takes full advantage of the substitution the fine penalty is made to replace the punishment against freedom and enhances the discretion of the court. It lets the court weight the criminal's financial capability and his social harmfulness, embodying the positive significance of the tendency of lightening penalty.

Secondly, thinking from the principle of the penalty individualization and humanization, it suggests adding the exchanging system of punishment against freedom. Based on the designing and performance of penalty exchanging system from different countries, the nature of the fine penalty exchanging is an accommodation. Usually the fine penalty is exchanged to alternative measures that do not belong to penalties such as the community service, reprimand, penal servitude and voluntary labor. As to the criminals who have zero capability to pay the fine but labor, it suggests without depriving of their liberty making them work in the designated public places and linking their labor time and intensity to the unpaid fine. That means using their labor remuneration or their labor pays the fine. The daily management of the criminals could be combined with the community's correction system. The grassroots' judicial office will be responsible for it. As to the criminals who have the ability to pay but maliciously evade paying, transferring, concealing or damaging their property resulting in the failure of fine execution, their penalty should be considered to be exchanged to detention or fixed-term imprisonment with a short term of shorter than 3 years. The criminals who have server crimes that violate the prohibitive regulations in the Criminal Law should be convicted and sentenced as the crime of refusing to execute judgments or 
orders of the People's Court in accordance with the law.

\section{B. Clarify the Fine-penalty Enforcement Organization}

In terms of the penalty's nature of the coercive measure of property, the Regulations on Issues Applied to Propertyrelated Penalties issued by the Supreme People's Court in 2010 clearly states that the property-related penalties should be executed by the organization that is responsible for sentence and execution in the Court of First Instance. That means the enforcement organization in the court becomes the main body enforcing the execution. Now the courts at each level form the Executive Board, below which there establish some specialized agencies such as Executive Tribunal and Execution Office. It announces the separation of execution and judgment to meet the needs of managing and coordinating the execution; however, from the perspective of personnel disposition and duty belongs, the Executive Board and the Executive Tribunal do not have clear partitions, which could be understood as having the same function under two different names. Setting up a tribunal under a board actually hides the logical mess existing in the administrative power leading the judicial power. This makes the Executive Tribunal impossible to perform the supervision over the execution.

The common measures taken by many countries is that to make the executive organization specialized, the organization structuring independent and to let the police become the main body of execution, which is also proved to be an effective and matured program. It suggests setting up an Execution Command Center in the internal pilot in Chinese courts, which will be directly managed by the Vice President who is responsible for the execution and dealing with the internal and external coordination in the execution. Taking a reference of the UK and Russian's cases, the judicial police under the Execution Board should be in dual management. That means the judicial police specializes in the execution and follows the unified arrangement and deployment issued by the Command Center; meanwhile, via the legislation clarifies the issues about the judicial police such as their obligation, status and their difference from the manning quota of the judges and confirms their presence being the legal status of executors. The Executive Tribunal will supervise the work of abovementioned two organizations. This will completely correct the mess caused by the crossover of the work from Judicial Tribunal and the Executive Board and the improper practice of collecting the fine from the criminal before sentencing him taken by the Judicial Tribunal to avoid the difficulty of execution.

\section{Establish the Property Investigation and Preservation prior to the Judgment Institution}

Though the Supreme People's Court has clarified in the judicial interpretation that when sentencing the fine penalty, the court should consider the criminal's financial capability, from the current legislation, during the criminal proceedings, the Public Security Bureau or the Procuratorate who is responsible for the investigation and the censoring has no legal duty to initiate an investigation of the criminal's financial capability. With the failure to initiate an investigation and evidence collection, the Court is surely not able to investigate or has no institutional restriction available to investigate the criminal's financial capability. This results in the rare evidence on the criminal's financial capability present in the trial materials, which makes the requirements in the judicial interpretation become a wild wish. In order to prevent enlarging the risks of execution difficulties such as the criminal maliciously transfers, conceals or damages the property in the course of investigation, it is necessary to track the property transferring, to perform the property preservation prior to starting the criminal proceedings on the criminal to whom the fine penalty could be applied and to build the specialized and complete archives on the criminals' financial status. It suggests transferring the tasks of financial investigation in the course of investigation to the Public Security Bureau and that of the criminal self-investigating cases could be done by the Procuratorate. The related findings together with the investigation materials in the course of investigation are transferred to the Procuratorate[4]. In the course of prosecution and judgment, the materials will be supervised by the Procuratorate and the Court respectively. If the Court affirms the findings on the criminal's financial status are unclear, it could be returned to the Public Security Bureau or the Procuratorate to do the additional investigation. If necessary, the Public Security Bureau or the executive organization is responsible for taking the property-preserving measures such as detaining or freezing the assets and offering the guarantees.

In view that now in the judicial practice, there exists a universal phenomenon that the court collects the fine before sentencing the criminal who pays the fine in advance. It could be rectified via building the bail bond for execution of the fine penalty. That means after proposing the public prosecution of convicting the criminal of fine penalty, in the premise that the truth of the case has been ascertained that the criminal should bear the corresponding criminal responsibility, the Defendant or his close relatives should be willing to pay a certain amount of the bail bond. The specific amount will be determined by the Court after having a comprehensive consideration of the criminal's crime, its hazardous consequence and his financial status, etc[5]. For example, consider the value the criminal devotes to his crime, the value he gains from the crime and the loss he directly causes, etc. The Court who receives the bail bond should issue a formal invoice to the payer. The invoice will be regarded as an evidence for charging against the fine after the judgment and also a consideration for the discretion on the sentence in the court. Besides, the verdict will clearly state the fact that the criminal currently pays the bail bone.

It is an irresistible trend of penalty lightening and individualizing. As an important part of the property-oriented penalty, the fine penalty will necessarily play a more significant and positive role in the future penalty theory and practice. Though the difficulty of fine penalty is universal, there will come out a smarter resolution to solve this problem for sure. I hope my opinions from the perspective of juridical 
practice and its operability could make a contribution to solving the difficulty of executing the fine penalty.

\section{Conclusion}

Despite that the difficulty of executing the fine penalty becomes universal, this issue still has not gained its due attention either in the criminal substantive laws or in the procedural law-studying field. This article tries to develop systematic research covering from the executing way of fine penalty, reasons of executing difficulty to the improvements of related mating systems and others and to propose the applicable range of adjusted fine penalty, add the criminal fine exchanging institution, clarify the enforcement organization and implement in the pilot the property investigation and preservation prior to judgment institution, etc., which hopefully could make a contribution to the research of the execution of punishment.

\section{References}

[1] HE Bojie, "The Solutions to China's Difficulty of Executing the Fine Penalty" Journal of Yangtze University (Social Sciences), 2010.

[2] YU Xifu., "The innovation of the civil enforcement system", The people's court Press, 2003.

[3] WANG, Qijiang "Research on Execution of Fine Penalty" Law Press, 2012.

[4] WANG Qijiang, "Research on Execution of Fine Penalty", Law Press, 2012.

[5] ZENG yan, and TIAN yu, "The perfect measures of Fine Penalty's discretion principles" The theoretical circle,2010. 